\title{
EFFECTS OF CAFFEINE AND/OR NASAL CPAP TREATMENT ON LARYNGEAL CHEMOREFLEXES IN PRETERM LAMBS
}

Nadia Boudaa ${ }^{\dagger}$, Nathalie Samson ${ }^{\dagger}$, Vincent Carrière $^{\dagger}$, Pamela Samanta Germim ${ }^{\dagger}$,JeanCharles Pasquier ${ }^{\delta}$, Aida Bairam*, Jean-Paul Praud ${ }^{\dagger}$

† Neonatal Respiratory Research Unit, Departments of Pediatrics and Physiology; Université de Sherbrooke, QC, Canada - J1H 5N4

* Department of Pediatrics, Université Laval, Centre de Recherche (D0-711), Hôpital St.-François d'Assise, Quebec, QC, G1L 3L5

${ }^{\delta}$ Department of Obstetrics and Gynecology, Université de Sherbrooke

Short title: Caffeine, nasal CPAP and laryngeal chemoreflexes

\section{Address for correspondence and proofs:}

Jean-Paul Praud MD PhD

Departments of Pediatrics and Physiology

Université de Sherbrooke

J1H 5N4, QC Canada
Phone: (819) 346-1110, ext 14851

Fax: (819) 564-5215

email: Jean-Paul.Praud@USherbrooke.ca 


\section{ABSTRACT}

Current knowledge suggests that laryngeal chemoreflexes (LCR) are involved in the occurrence of certain neonatal apneas/bradycardias, especially in the preterm newborn. While caffeine and/or nasal continuous positive airway pressure (nCPAP) are the most frequent options used for treating apneas in preterm newborns, their effects on LCRrelated apneas/bradycardias are virtually unknown. The aim of the present study was to test the hypothesis that caffeine and/or nCPAP decreases LCR-related cardiorespiratory inhibition in a preterm ovine model. Seven preterm lambs were born vaginally on gestational day 133 (normal gestation: 147 days) after intramuscular injections of betamethasone and mifepristone. Five days after birth, a chronic surgical instrumentation was performed to record states of alertness, electrocardiogram, systemic arterial pressure and electromyographic activity of a laryngeal constrictor muscle as well as to insert a transcutaneous, supraglottal catheter. Laryngeal chemoreflexes were induced in quiet sleep during 4 randomized conditions: 1) control (without caffeine or nCPAP); 2) nCPAP (5 $\mathrm{cm} \mathrm{H}{ }_{2} \mathrm{O}$, without caffeine); 3) caffeine $(10 \mathrm{mg} / \mathrm{kg}$ infused intravenously in 30 minutes, without nCPAP); and 4) nCPAP + caffeine. While nCPAP consistently blunted the LCR-related apneas/bradycardias, the effect of caffeine was inconsistent and on average not significant. In addition, the effect of caffeine + nCPAP was less beneficial than nCPAP alone. In conclusion, our unique results show that, contrary to caffeine, nCPAP consistently improves LCR-related cardiorespiratory inhibition in preterm lambs. Beyond their potential physiological 
significance, our results suggest that nCPAP may be superior to caffeine for treating neonatal apneas linked to LCR.

KEYWORDS: Quiet sleep; apneas of prematurity; mifepristone; swallowing; arousal response 


\section{INTRODUCTION}

Laryngeal chemoreflexes (LCR) are a group of reflexes triggered by the contact between a liquid and the laryngeal mucosa and are primarily aimed at preventing tracheal aspiration $(29,39)$. In a mature mammal, including in the healthy full-term newborn, LCR include cough, deglutition and arousal (37). However, in the immature newborn mammal such as the preterm lamb, LCR rather encompass significant and, at times, life-threatening apneas, bradycardias and desaturations (38); treatment is currently unknown. Relevance for the study of LCR pertains to their likely involvement in neonatal pathologies linked to abnormalities of cardiorespiratory control, such as apneas of prematurity $(\mathrm{AOP})(29,39)$.

Apneas of prematurity represent a very frequent and worrisome pathology, which affects $50 \%$ of all newborns before 37 weeks of gestation and virtually all extremely premature infants born before 28 weeks of gestation (40). Though a number of AOP can be prevented by either avoiding triggers or prone positioning or can be halted by gentle cutaneous stimulations, further treatment is often needed (28). Caffeine and nasal CPAP (nCPAP) undoubtedly represent the mainstay of treatment for severe AOP. However, additional intervention in the form of nasal or even endotracheal intermittent positive pressure ventilation is sometimes necessary (42). Apneas of prematurity have a complex physiopathology, mainly related to immaturity of respiratory control (24). And while immature respiratory reflexes such as LCR are involved in some AOP in response to triggers such as laryngeal penetration of upper airway secretions or gastric refluxate or during milk or vitamin ingestion $(29,39)$, the effects of caffeine and/or nCPAP on 
LCR-related cardiorespiratory events are virtually unknown. Very preliminary results on the effect of caffeine administered in a non-controlled manner in 3 preterm lambs suggested that caffeine prevents severe LCR-related cardiorespiratory events (38). The aim of the present study performed in our unique ovine preterm model was therefore to test the hypothesis that caffeine and/or nCPAP can prevent LCR-related cardiorespiratory events. 


\section{MATERIAL AND METHODS}

\section{Animals}

Experiments were performed in seven preterm lambs with a postconceptional age of 133 days (normal gestation: 147 days) and a mean birth weight of $3.11 \mathrm{~kg}$ (SD 0.61) (range: $2.14-4.24 \mathrm{~kg}$ ). The protocol of the study was approved by the Ethics Committee for Animal Care and Experimentation of the Université de Sherbrooke.

\section{Preterm lamb model}

Seven preterm lambs were born vaginally on gestational day 133. An ultrasound to confirm pregnancy, as well as the number of lambs and their viability was performed a few days prior to induction of premature labor in all ewes. To induce premature labor, ewes first received two intramuscular injections of $12 \mathrm{mg}$ betamethasone on gestational days 131 and 132 to stimulate lung surfactant maturation (11). Secondly, on gestational day 132, an intramuscular injection of mifepristone (RU 486, a progesterone receptor antagonist, $8 \mathrm{mg} / \mathrm{kg}$ ) was administered to all ewes (15). Thereafter, ewe behavior was carefully monitored by video surveillance, followed by one or more vaginal examinations until lambing. Lambing occurred on average 30 hours (SD 3) (range: 26 - 36h) after mifepristone injection. Delivery was only assisted in case of dystocia to prevent fetal neurological distress. During the first $48 \mathrm{~h}$ following birth, vital signs, including temperature, heart and respiratory rate, oxygen saturation, blood glucose level and weight were meticulously monitored. If needed to maintain normal vital signs, lambs were placed under a heated lamp, received reconstituted ewe's colostrum or milk by 
bottle or feeding tube. The presence of an experimenter $24 \mathrm{~h} / 24$ during the first $48 \mathrm{~h}$ was deemed necessary to perform these vital tasks, as well as for assisting the preterm lamb in its attempts at successful interactions with its mother.

\section{Chronic Instrumentation}

Chronic instrumentation was performed on the 5th day of life under general anesthesia (2\% isoflurane, $30 \% \mathrm{~N}_{2} \mathrm{O}$, balance $\mathrm{O}_{2}$ ), as recently described (8). Briefly, anesthesia was preceded by an intramuscular injection of ketamine $(5 \mathrm{mg} / \mathrm{kg})$, atropine sulfate $(0.1$ $\mathrm{mg} / \mathrm{kg})$ and morphine $(0.016 \mathrm{ml} / \mathrm{kg})$ and an intravenous bolus $(10 \mathrm{ml} / \mathrm{kg})$ of Ringer's lactate solution. One dose of ketoprofen $(3 \mathrm{mg} / \mathrm{kg})$ was also injected intramuscularly for analgesia and repeated if needed the next day. Antibiotics $(5 \mathrm{mg} / \mathrm{kg}$ gentamicin and 50 mg ampicillin, twice a day) were administered intramuscularly prior to surgery and daily thereafter.

As previously described (8), two right-angled needle-electrodes (E7-12, Grass Technologies, West Warwick, RI, USA) were inserted into the parietal cortex directly through the skull for electrocorticogram $(E C o G)$ recordings, while a third needleelectrode (F-E2M, Grass Technologies) was inserted under the scalp as a ground. Eye movements (EOG) were recorded with two custom-built silver electrodes inserted subcutaneously next to the right eye socket. The electrocardiogram (ECG) was recorded with 2 needle-electrodes (F-E2M, Grass Technologies) inserted under the periosteum of the $5^{\text {th }}$ rib, on both sides of the thorax, and directly glued on the ribs. For electrical activity (EMG) recording, custom-designed bipolar electrodes, built from right- 
angled gold connectors (Sullins Connector Solution, Digi-Key Corporation, Thief River Falls, MN, USA), were inserted into both thyroarytenoid muscles (TA; a glottal constrictor) through the lateral aspect of the thyroid cartilage. Both electrodes were then glued on the external surface of the thyroid cartilage. A catheter was also introduced into the right carotid artery to monitor arterial blood pressure and blood gases. In addition, a supraglottal catheter was inserted transcutaneously to allow injection of liquids into the laryngeal vestibule (13). Finally, a plastic tubing (internal diameter $1 \mathrm{~mm}$ ) was subcutaneously tunneled to the lamb's back in order to connect the external part of the supraglottal catheter to our custom-built, radio telemetry-driven injector. Leads from each electrode and catheter were subcutaneously tunneled to a common exit on the lamb's back. Post-operative care included antibiotics and daily flushing of the arterial catheter with heparin solution. Lambs were euthanized at the end of experiments by pentobarbital overdose $(100 \mathrm{mg} / \mathrm{kg})$. Correct electrode and catheter positioning was systematically verified at necropsy.

\section{Experimental equipment}

Ventilatory equipment

Nasal CPAP was applied using the Infant Flow nCPAP system (Cardinal Health, Dublin, $\mathrm{OH}$, USA) with heated $\left(37^{\circ} \mathrm{C}\right)$, humidified air. A custom-built nasal mask, filled with dental paste (Examix, Servident, St-Laurent, Qc, CAN), was installed on the lamb's muzzle to deliver nCPAP while enabling the lamb to open its mouth at will (5). 


\section{$\underline{\text { Recording equipment }}$}

Lamb instrumentation was completed immediately before recordings. Elastic bands for respiratory inductance plethysmography (Respitrace, NIMS, Miami Beach, FL, USA) were installed around the thorax and abdomen to monitor respiratory movements and to assess lung volume variations qualitatively. Nasal CPAP values were continuously monitored from the nasal mask (RX104A pressure transducer, Biopac Systems, Goleta, CA, USA). A reflectance pulse oximeter sensor (Masimo Radical, Irvine, CA, USA) was attached at the base of the tail for continuous monitoring of oxygen hemoglobin saturation $\left(\mathrm{SpO}_{2}\right)$ as well as pulse wave. Arterial blood gases were also measured in four lambs (IL 1306, Instrumentation Laboratory, Lexington, MA, USA) and corrected for rectal temperature of the lamb (1). Finally, the subcutaneous plastic tubing connected to the supraglottal catheter was attached to a custom-built, radio telemetry-driven injector, where liquids to be injected were warmed and maintained at the lamb's body temperature. All recordings were performed using our custom-designed radio telemetry system (33) in order to obtain prolonged recordings in non-sedated lambs under the least possible restraining conditions. The raw EMG signals were rectified, integrated, and moving time averaged (100 ms). All parameters were continuously recorded on a PC using AcqKnowledge software (version 4.1; Biopac Systems, Goleta, CA, USA).

\section{Design of the study}

All preterm lambs were housed and cared for with their mother in our animal quarters until the experimental day. Polysomnographic recordings were performed on postnatal days 7 and $8(n=5)$ or postnatal days 8 and $9(n=2)$ and included simultaneous 
recording of respiratory movements, states of alertness, TA EMG, ECG, systemic arterial blood pressure and $\mathrm{SpO}_{2}$. Accordingly, lambs were placed in a Plexiglas chamber $(1.2 \times 1.2 \times 1 \mathrm{~m}$, corresponding to guidelines from the Canadian Council for Animal Care) and comfortably positioned on a mattress with minimal contention (under the constant presence of an experimenter near the lamb to prevent agitation and ambulation when it was connected to nCPAP). Arterial blood gases and $\mathrm{pH}$ were measured in four lambs before each of the four experimental conditions in order to eliminate the presence of baseline hypoxia, hypercapnia and/or a low $\mathrm{pH}$, which have been shown to affect $\operatorname{LCR}(17,18)$. Laryngeal chemoreflexes were induced by injection of $0.5 \mathrm{ml}$ of hydrochloric acid $(\mathrm{HCl}, \mathrm{pH}=2$, diluted in saline) or ewe milk via the supraglottal catheter during quiet sleep (QS). Both solutions were injected twice in random order during four experimental conditions: 1) control (without caffeine or nCPAP); 2) nCPAP (5 cm $\mathrm{H}_{2} \mathrm{O}$, without caffeine; 3) caffeine $(10 \mathrm{mg} / \mathrm{kg}$ infused intravenously in 30 minutes, without nCPAP); and 4) nCPAP + caffeine. Due to the long half-life of caffeine in the newborn (2), the two experimental conditions involving caffeine had to be performed on the second recording day. On each day, the order of the 2 experimental conditions (with and without nCPAP) was randomized. The supraglottal catheter was systematically flushed with $1 \mathrm{ml}$ of saline between each injection of test solutions (dead space of the catheter $0.5 \mathrm{ml}$ ) and each lamb was given at least $15 \mathrm{~min}$ of recovery time between two injections. Events such as agitation, cough, arousal and/or full awakening were noted by an observer throughout the recordings. Finally, 
plasma caffeine level was systematically measured at the end of the second recording day.

\section{Data analysis}

States of alertness

Standard electrophysiological and behavioral criteria were used to define quiet sleep (QS) (31). Cortical arousal from QS was defined by the association of a change in ECoG (decrease in amplitude + increase in frequency) for $3 \mathrm{~s}$ or more, with at least two of the following modifications: a $10 \%$ increase in heart rate $(\mathrm{HR})$ or change in respiratory rate $(R R)$ or movement (21). Full awakening was defined when the lamb was still awake after $1 \mathrm{~min}(16)$.

\section{$\underline{\text { Laryngeal chemoreflexes }}$}

Analysis of the LCR was performed as described previously within the first minute following each laryngeal injection (38). First, cardiorespiratory responses were assessed as follows. The percentage of decrease in $H R\left[\% D e c H R=\left(H R_{B L}-H R_{\min }\right) x\right.$ $\left.100 / H R_{B L}\right]$ was calculated, with $H R_{B L}$ representing the baseline $H R$ value averaged over $30 \mathrm{~s}$ before challenge, and $H R_{\min }$ representing the minimal $H R$ value observed during the first minute after the challenge. The $\% \mathrm{Dec} \mathrm{SpO}_{2}$ was calculated in the same manner. Any presence of bradycardia (defined by a \%Dec HR > 33\%) was noted, as well as the number of bradycardias and total summed duration of bradycardias. The presence of apneas (defined as at least two missed breaths relative to baseline 
breathing) was also noted, including the number of apneas and their total summed duration. Moreover, any presence of desaturation was noted, as defined by a decrease in $\mathrm{SpO}_{2}$ of at least $4 \%$ or $<90 \%$, as well as the minimal $\mathrm{SpO}_{2}\left(\mathrm{SpO}_{2 m i n}\right)$. The percentage of increase (\%Inc) in MAP was also noted. For all stimulations, the time duration between the moment of stimulation and the moment of $H R_{\min }$, the onset of the first apnea, $\mathrm{SpO}_{2 m i n}$ and MAP occurrence (respectively $\mathrm{HR}_{\min }$, apnea, $\mathrm{SpO}_{2 m i n}$ and MAP occurrence times) were measured. In addition to cardiorespiratory responses, the following responses, usually considered to be protective against tracheal aspiration (29), were assessed. First, the number of swallows (defined as a brisk, high-amplitude, and short-duration TA EMG burst) (30) occurring within the first minute after laryngeal stimulation was tallied. Secondly, the number of coughs (including laryngeal expiratory reflexes, which could not be discerned from coughs in our study) was also inferred from visual observations, as well as analysis of TA EMG and respiratory inductance plethysmograph signals. Lastly, the presence of arousal or full awakening was noted.

\section{$\underline{\text { Statistical analysis }}$}

Results were first averaged in each lamb and then averaged for the 7 lambs as a whole. Quantitative data were expressed as mean (SD), whereas qualitative binary data (arousal and awakening, yes/no) were expressed as relative frequency. Statistical data analyses were performed on raw data for all variables. Quantitative continuous data were analyzed through a general linear model 2-way ANOVA for repeated measures using PROC MIXED of the SAS software (version 9.1, Cary, NC), with treatment 
(nCPAP and/or caffeine) and solutions ( $\mathrm{HCl}$ or ewe milk) as the independent variables. Binary data were analyzed with a logistic regression model using the GENMOD procedure of the SAS software while count data (number of coughs, swallows) were analyzed by the Friedman's test followed by the Wilcoxon's signed rank test, using the GraphPad Prism software (version 5.0, La Jolla, CA). Differences were deemed statistically significant if $p<0.05$. In addition, given the relatively small number of studied lambs (related both to the complexity of the preterm ovine model and ethical constraints), it was decided to give full consideration to the presence of a significant trend, defined as $p<0.1$. 


\section{RESULTS}

\section{Premature lamb model}

Seven pregnant ewes were included in the study. Lambing occurred on average 30 (3) hours (range 26 - 36 h) after mifepristone injection, on gestational day 133 . The total number of births was 12, including 6 females and 6 males with 5 ewes delivering twins and 2 ewes delivering a single lamb. Eleven of the twelve preterm lambs survived, with two lambs from the same litter needing resuscitation at birth due to severe dystocia. One of these twins was stillborn and could not be resuscitated. One lamb was found cyanotic and bradycardic $24 \mathrm{~h}$ after birth (following a prolonged apnea of prematurity?), but was successfully resuscitated. All the other lambs did not require oxygen at birth and presented normal vital signs from birth to the last day of experimentation (Table 1). Lamb feeding initially began by presentation of the ewe's teat for a maximum of 5 minutes at approximately every 2 hours and was followed, if needed, by supplemented bottle-feeding (ewe colostrum or milk). Two lambs were tube-fed during the first 24 hours of life due to a poor sucking reflex. All lambs were self-sufficient in feeding after 24 to 48 hours of life.

\section{Effects of nCPAP and/or caffeine treatment}

\section{Baseline cardiorespiratory values}

Baseline cardiorespiratory values obtained in all 7 lambs and in each experimental condition are detailed in Table 2. Overall, nCPAP alone or combined with caffeine decreased RR and increased MAP as well as $\mathrm{SpO}_{2}$ (see Table 2 for details on specific 
interactions). In addition, baseline arterial blood gases and $\mathrm{pH}$ measured in $4 / 7$ lambs

were found normal in all experimental conditions: $\mathrm{PaO}_{2}=80$ (4) $\mathrm{mmHg}$ (range 76-88 $\mathrm{mmHg}$ ); $\mathrm{PaCO}_{2}=41$ (2) $\mathrm{mmHg}$ (range $39-45 \mathrm{mmHg}$ ); $\mathrm{pH}=7.36$ (0.01) (range 7.347.37).

\section{Laryngeal chemoreflexes}

A total of 111 laryngeal stimulations were performed during QS; one LCR (milk) was not induced as one caffeine-treated lamb was unable to sleep during the recording. Plasma caffeine level in the 7 lambs was 58 (6) $\mathrm{mg} / \mathrm{L}$ (range 35-67 mg/L) after completion of the second recording session, approximately 4 hours after caffeine infusion.

Life-threatening cardiorespiratory events were observed in $3 / 7$ lambs following $\mathrm{HCl}$ injection in control, caffeine and nCPAP/caffeine conditions. These events included repetitive, prolonged central apneas or periodic breathing epochs with bradycardias (minimum HR 32 beats/min) and hemoglobin desaturation (minimum $\mathrm{SpO}_{2}=20 \%$ ). The events lasted from $95 \mathrm{sec}$ to $9 \mathrm{~min}$ before spontaneous recovery (Fig. 1). No severe cardiorespiratory event was observed under nCPAP condition in any of the lambs.

Laryngeal chemoreflexes-related cardiorespiratory events. Cardiorespiratory events obtained during LCR are summarized in Figure 2 and Table 3, and are illustrated by tracings obtained in one lamb in the 4 experimental conditions in Figure 3. $\mathrm{SpO}_{2}$ was analyzed in only 5 lambs due to technical difficulties (one black lamb, hence the reflectance sensor unable to analyze blood color, and one lamb with its tail severely bitten by the ewe). Overall, nCPAP significantly blunted the LCR-related cardiorespiratory components elicited by $\mathrm{HCl}$ compared to control and to caffeine 
treatment. A beneficial effect of nCPAP treatment was observed for apnea number and/or duration, as well as for bradycardia number and/or duration and for the \%Dec $\mathrm{HR}$. In addition, minimal $\mathrm{HR}$ and $\mathrm{SpO}_{2}$ values were higher during $\mathrm{nCPAP}$ treatment (see Table 3 for details on specific interactions). Although cardiorespiratory inhibition was less pronounced following milk injection, it was similarly blunted under nCPAP treatment compared to control and caffeine treatment (Table 3). By contrast, caffeine alone or when combined with nCPAP had no significant effect, on average, on LCR-related cardiorespiratory inhibition. Further analysis revealed that, contrary to nCPAP, the effect of caffeine was notably variable from one lamb to another for apnea number and/or duration (Fig. 4A), as well as for bradycardia number and/or duration for both $\mathrm{HCl}$ (Fig. 4B) and milk.

Protective mechanisms observed during laryngeal chemoreflexes. The protective mechanisms observed during LCR are summarized in Table 4. Overall, the \%Inc MAP was decreased during nCPAP and nCPAP + caffeine treatment compared to control, independently of the solution used to induce the LCR. While no differences between treatments for either solutions were observed for awakening, a greater number of arousals was noted during nCPAP + caffeine treatment compared to control, following $\mathrm{HCl}$ injection only $(p=0.05)$. Finally, while no differences between treatments were noted for the number of swallows, a greater number of coughs were observed after caffeine administration when compared to nCPAP alone or combined with caffeine following $\mathrm{HCl}$ injection only, whereas no differences were otherwise noted between treatments and control condition. 


\section{DISCUSSION}

\section{Statement of principal findings}

The present study provides new and intriguing findings on the effects of nCPAP and/or caffeine on laryngeal chemoreflexes in preterm lambs. Indeed, nCPAP blunted LCRrelated cardiorespiratory inhibition, contrary to caffeine alone or combined with nCPAP; minimal effects were noted on the so-called protective mechanisms such as swallowing, coughs, arousal responses and awakenings. Moreover, while the effects of nCPAP treatment on cardiorespiratory events were consistent in most lambs (6/7 lambs), the effect of caffeine was notably variable from one lamb to another.

\section{Our preterm lamb model}

Over the years, many improvements have been made to our preterm lamb model, which has resulted in an important increase in the survival rate and health outcome of our animals $(3,30,31,38)$. Previously, intensive neonatal care, including delivery by caesarean section under epidural anesthesia, immediate endotracheal intubation at birth to deliver exogenous surfactant replacement, supplemental nasal oxygen and tube feeding, were applied, with an average survival rate of roughly $50 \%$ at day 7 of life (3, $30,31,38)$. In contrast, $11 / 12$ preterm lambs delivered in the present study survived (one stillborn lamb due to severe dystocia) with constant care focusing on optimal ewelamb interactions during the first 48 hours of life while eliminating invasive procedures. This intensive, albeit non-invasive neonatal care probably explains our high survival rate 
(>90\%), which compares favorably to the rates recently reported by others for a similar preterm ovine model (9).

\section{Effects of caffeine and/or nCPAP treatment on laryngeal chemoreflexes}

Caffeine is undoubtedly the first line treatment for severe AOP, due to both its general efficiency in reducing AOP and its relative short term and long term safety profile, including up to school-age $(2,25,34,35)$. Caffeine is both a powerful central nervous system stimulant and respiratory stimulant. The latter is partly related to its potent $A_{1}$ and $A_{2}$ adenosine receptor antagonist action and includes an increase in minute ventilation and $\mathrm{CO}_{2}$ sensitivity as well as a decrease in hypoxic depression and periodic breathing (23). However, caffeine alone can be insufficient to treat AOP (6) and nCPAP (4-6 $\mathrm{cmH}_{2} 0$ ) must often be added to caffeine for an optimal effect on AOP. Nasal CPAP functions by decreasing upper airway obstruction and work of breathing and by increasing functional residual capacity and pulmonary oxygen stores $(10,24,42)$. However, although nCPAP and caffeine are widely used for AOP treatment, their effects on LCR-related apneas and bradycardias are still unknown.

\section{Blunting of LCR-related cardiorespiratory inhibition by nCPAP}

Nasal CPAP increases laryngeal opening in preterm infants (14) and decreases nonnutritive swallowing frequency in newborn lambs (32). This could conceivably increase the contact time of liquid with the laryngeal mucosa and consequently enhance LCRrelated cardiorespiratory inhibition. On the contrary, the present study reveals that an nCPAP of $5 \mathrm{cmH}_{2} \mathrm{O}$ blunts LCR-related cardiorespiratory events and arterial oxygen 
desaturation in preterm lambs, as opposed to caffeine alone or combined with nCPAP. The increase in pulmonary oxygen stores under nCPAP likely contributed to preventing desaturations and bradycardias following LCR-related apneas (10, 24). However, the mechanism underlying the beneficial effects of nCPAP on apneas is unclear. In particular, nasal CPAP did not decrease swallowing activity, a well-known respiratory inhibitor.

High variability of caffeine effects on LCR-related cardiorespiratory inhibition

Previous preliminary results in only 3 preterm lambs treated with caffeine (one intravenous infusion of $10 \mathrm{mg} / \mathrm{kg}$ ) for clinically significant apneas and bradycardias, 3 days prior to LCR studies, led to the hypothesis that caffeine treatment was an efficient means to prevent LCR-related cardiorespiratory events (38). However, results from the present study show a very variable effect of caffeine, with a blunting of the LCR-related cardiorespiratory inhibition being observed in only $2 / 7$ preterm lambs (figure 4 ). Such variable effect of caffeine has also been reported in preterm infants for AOP reduction $(12,19,26)$, as well as a failure to prevent hypoxemic episodes and bradycardias (7). Of note, the variability in caffeine effect in preterm lambs was not related to a variable arousal and/or awakening response during LCR, since the latter did not differ between treatments.

\section{Protective mechanisms related to laryngeal chemoreflexes}

Aside from cardiorespiratory events, laryngeal chemoreflexes also elicit coughing, swallowing, arousal and awakening. These components of the LCR are considered to 
be protective mechanisms aimed at both clearing liquids from the laryngeal region and preventing tracheal aspiration. The absence of effects of nCPAP on swallowing during LCR may appear surprising, given our previous report that non-nutritive swallowing is decreased by nCPAP via reflexes originating from bronchopulmonary receptors (32). However, our recent study showing that nCPAP (up to $10 \mathrm{cmH}_{2}$ ) does not decrease nutritive swallowing (5) likely indicates that the inhibiting effect of nCPAP on swallowing does not operate in instances of urgency, when repetitive swallowing is deemed crucial by the swallowing centers to prevent tracheal aspiration. To our knowledge, there have been no previous reports of the effect of caffeine on swallowing.

While in the present study, the administration of caffeine increased the number of coughs when compared to nCPAP alone or combined with caffeine, the precise mechanism underlying this effect remains unclear. Finally, while the positive effect of nCPAP/caffeine on arousal may seem in agreement with the well-known neurostimulant effect of caffeine, including in human infants (4), the absence of any effect of caffeine alone remains unexplained.

\section{Clinical implications}

The present results, although obtained in lambs, suggest that nCPAP treatment is especially relevant for AOP related to LCR, as observed in preterm infants with laryngeal penetration of upper airway secretions or gastric refluxate. However, among infants presenting with AOP, the proportion suffering from LCR-induced cardiorespiratory events is currently unknown $(27,36)$. In addition, two important 
questions need to be addressed and relate to the effects of nCPAP on the number and characteristics of gastric refluxes and on cardiorespiratory reflexes originating from esophageal receptors in instances of esophageal distension (20). Moreover, it is noteworthy that while nCPAP markedly reduces gastric reflux frequency in adult humans with obstructive sleep apneas (22), nCPAP has been shown to increase the gastroesophageal pressure gradient, and thus the risk of gastric refluxes, in adult rats (41). 


\section{ACKNOWLEDGMENTS}

The authors gratefully acknowledge the expert technical assistance of Jean-Philippe Gagné and the guidance of Julie Hamon and Nathalie Carrier for statistical analyses. The study was supported by grants from the Canadian Institutes of Health Research and the Foundation of Stars (Quebec) allocated to J-P Praud. Jean-Paul Praud is a member

of the FRSQ-funded Clinical Research Center Étienne-Le Bel, Sherbrooke University Hospital, and the holder of the Tier 1 Canada Research Chair in Neonatal Respiratory Physiology.

\section{Contributions of authors}

Nadia Boudaa: surgical instrumentation, postoperative animal care, recordings, analyses, manuscript writing Nathalie Samson: design of the study, surgical instrumentation, recordings, interpreted results of experiments, manuscript writing Vincent Carrière: analyses of the results Pamela Samanta Germim: postoperative animal care Jean-Charles Pasquier: design of the study Aida Bairam: design of the study, manuscript writting Jean-Paul Praud: design of the study, interpreted results of experiments, manuscript writing 


\section{REFERENCES}

1. Andritsh RF, Muravchick S, Gold MI. Temperature correction of arterial blood-gas parameters: A comparative review of methodology. Anesthesiology 55: 311-6, 1981.

2. Aranda JV, Beharry K, Valencia GB, Natarajan G, Davis J. Caffeine impact on neonatal morbidities. J Matern Fetal Neonatal Med 23(S3): 20-3, 2010.

3. Arsenault J, Moreau-Bussiere F, Reix P, Niyonsenga T, Praud JP. Postnatal maturation of vagal respiratory reflexes in preterm and full-term lambs. $J$ Appl Physiol 94: 1978-86, 2003.

4. Barry RJ, Clarke AR, Johnston SJ, Brouw CR, Bruggemann JM, Van Rijbroek. Caffeine effects on resting state arousal in children. Int J Psychophysiol 73: 355-61, 2009.

5. Bernier A, Catelin C, Hadj-Ahmed MA, Samson N, Bonneau P, Praud JP. Effects of nasal continuous positive airway pressure on nutritive swallowing in lambs. J Appl Physiol, In press, 2012.

6. Bhatt-Mehta V, Schumacher RE. Treatment of apnea of prematurity. Paediatr Drugs 5: 195-210, 2003.

7. Bucher HU, Duc G. Does caffeine prevent hypoxaemic episodes in premature infants? A randomized controlled trial. Eur J Pediatr 147: 288-91, 1988.

8. Carreau AM, Patural H, Samson N, Doueik AA, Hamon J, Fortier PH, Praud JP. Effects of simulated reflux laryngitis on laryngeal chemoreflexes in newborn lambs. J Appl Physiol 111: 400-6, 2011. 
9. De Matteo R, Snibson K, Thompson B, Koumoundouros E, Harding R. Lung function in developing lambs: is it affected by preterm birth? J Appl Physiol 107: 1083-8, 2009.

10. Diblasi RM. Nasal continuous positive airway pressure (CPAP) for the respiratory care of the newborn infant. Respir Care 54: 1209-35, 2009.

11. Eckman DM, Kerr BA, Fuloria M, Simandle SA, Watt SE, Rose JC, Fiqueroa JP. Antenatal betamethasone alters vascular reactivity in adult female ovine cerebral arteries. Pediatr Res 68: 344-8, 2010.

12. Erenberg A, Leff RD, Haack DG, Mosdell KW, Hicks GM, Wynne BA. Caffeine citrate for the treatment of apnea of prematurity: a double-blind, placebo-controlled study. Pharmacotherapy 20: 644-52, 2000.

13. Fortier PH, Reix P, Arsenault J, Dorion D, Praud JP. Active upper airway closure during induced central apneas in lambs is complete at the laryngeal level only. $J$ Appl Physiol 95: 97-103, 2003.

14. Gaon P, Lee S, Hannan S, Ingram D, Milner AD. Assessment of effect of nasal continuous positive pressure on laryngeal opening using fibre optic laryngoscopy. Arch Dis Child Fetal Neonatal Ed 80: F230-2, 1999.

15. Gazal OS, Li Y, Schwabe C, Anderson LL. Attenuation of antepartum relaxin surge and induction of parturition by antiprogesterone RU 486 in sheep. J Reprod Fertility 97: 233-40, 1993. 
16. Goto K, Mirmiran M, Adams MM, Longford RV, Baldwin RB, Boeddiker MA, Ariagno RL. More awakening and heart rate variability during supine sleep in preterm infants. Pediatrics 103: 603-9, 1999.

17. Heman-Ackah YD. Determinants of fatal apnea responses to acid stimulation of the larynx in piglets. Ann Otol Rhinol Laryngol 114: 509-16, 2005.

18. Heman-Ackah YD, Pernell KJ, Goding GS Jr. The laryngeal chemoreflex: an evaluation of the normoxic response. Laryngoscope 119: 370-9, 2009.

19. Henderson-Smart DJ, De Paoli AG. Methylxanthine treatment for apnoea in preterm infants. Cochrane Database Syst Rev (12): CD000140, 2010.

20. Jadcherla SR. Upstream effect of esophageal distention: effect on airway. Curr Gastroenterol Rep 8:190-4, 2006.

21. Kato I, Franco P, Groswasser J, Scaillet S, Kelmanson I, Togari H, Kahn A. Incomplete arousal processes in infants who were victims of sudden death. Am J Respir Crit Care Med 168: 1298-303, 2003.

22. Kerr P, Shoenut JP, Millar T, Buckle P, Kryger MH. Nasal CPAP reduces gastroesophageal reflux in obstructive sleep apnea syndrome. Chest 101: 1539$44,1992$.

23. Martin RJ, Abu-Shaweesh JM. Control of breathing and neonatal apnea. Biol Neonate 87: 288-95, 2005.

24. Mathew OP. Apnea of prematurity: pathogenesis and management strategies. $J$ Perinatol 31: 302-10, 2011. 
25. Mueni E, Opiyo N, English M. Caffeine for the management of apnea in preterm infants. Int Health 1: 190-5, 2009.

26. Paul K, Melichar J, Miletín J, Dittrichová J. Differential diagnosis of apneas in preterm infants. Eur J Pediatr 168: 195-201, 2009.

27. Poets CF. Apnea of prematurity: What can observational studies tell us about pathophysiology? Sleep Med 11: 701-7, 2010.

28. Poets CF. Interventions for apnoea of prematurity; a personal view. Acta Paediatr 99: 172-7, 2010.

29. Praud J-P. Upper airway reflexes in response to gastric reflux. Paediatr Respir Rev 11: 208-12, 2010.

30. Reix P, Fortier PH, Niyonsenga T, Arsenault J, Létourneau P, Praud JP. Nonnutritive swallowing and respiration coordination in full-term newborn lambs. Respir Physiol Neurobiol 42: 209-18, 2003.

31. Renolleau S, Letourneau P, Niyonsenga T, Praud JP. Thyroarytenoid mucle electrical activity during spontaneous apnes in preterm lambs. Am J Respir Crit Care Med 159: 1396-404, 1999.

32. Samson N, Roy B, Ouimet A, Moreau-Bussière F, Dorion D, Mayer S, Praud JP. Origins of the inhibiting effects of nasal CPAP on non-nutritive swallowing in newborn lambs. J Appl Physiol 105: 1083-90, 2008.

33. Samson N, Dumont S, Specq ML, Praud JP. Radiotelemetry devices to monitor breathing in non-sedated animals. Resp Physiol Neurobiol 179: 111-8, 2011. 
34. Schmidt B, Roberts RS, Davis P, Doyle LW, Barrington KJ, Ohlsson A, Solimano A, Tin W. Caffeine for Apnea of Prematurity Trial Group. N Engl J Med 354: 2112-21, 2006.

35. Schmidt B, Anderson PJ, Doyle LW, Dewey D, Grunau RE, Asztalos EV, Davis PG,Tin W, Moddemann D, Solimano A, Ohlsson A, Barrington KJ, Roberts RS. Caffeine for Apnea of Prematurity (CAP) Trial Investigators. Survival without disability to age 5 years after neonatal caffeine therapy for apnea of prematurity. JAMA 307: 275-82, 2012.

36. Slocum C, Hibbs AM, Martin RJ, Orenstein SR. Infant apnea and gastroesophageal reflux: a critical review and framework for further investigation. Curr Gastroenterol Rep 9: 219-24, 2007.

37. St-Hilaire M, Nsegbe E, Gagnon-Gervais K, Samson N, Moreau-Bussière F, Fortier PH, Praud JP. Laryngeal chemoreflexes induced by acid, water, and saline in nonsedated newborn lambs. J Appl Physiol 98: 2197-203, 2005.

38. St-Hilaire M, Samson N, Nsegbe E, Duvareille C, Moreau-Bussière F, Micheau P, Lebon J, Praud JP. Postnatal maturation of laryngeal chemoreflexes in the preterm lamb. J Appl Physiol 102: 1429-38, 2007.

39. Thach BT. Some aspects of clinical relevance in the maturation of respiratory control in infants. J Appl Physiol 104: 1828-34, 2008.

40. Theobald K, Botwinski C, Albanna S, McWilliam P. Apnea of prematurity: diagnosis, implications for care, and pharmacologic management. Neonatal Netw 19: 17-24, 2000. 
41. Wang W, Tovar JA, Eizaquirre I, Aldazabal P. Continuous positive airway pressure and gastroesophageal reflux: an experimental study. J Pediatr Surg 29: 730-3, 1994.

42. Zhao J, Gonzalez F, Mu D. Apnea of prematurity: from cause to treatment. Eur J Pediatr 170: 1097-105, 2011. 


\section{FIGURE LEGENDS}

\section{Figure 1}

Potentially life-threatening cardiorespiratory reflexes triggered in one preterm lamb following instillation of $0.5 \mathrm{ml} \mathrm{HCl}$ onto the laryngeal mucosa during quiet sleep in control condition (no nCPAP / no caffeine). From top to bottom: ECoG, electrocorticogram; EOG, electrooculogram; TA, electrical activity of the thyroarytenoid muscle (laryngeal constrictor); Lung volume, sum signal of the respiratory inductance plethysmograph, allowing qualitative measurement of respiration (inspiration upward); ECG, electrocardiogram; HR, heart rate (mean and maximum (max); beats/min); $\mathrm{SpO}_{2}$, hemoglobin $\mathrm{O}_{2}$ saturation; $\mathrm{AP}$, arterial pressure (mean and maximum (max); $\mathrm{mmHg}$ ). Note the prolonged, potentially life-threatening responses with awakening, repetitive apneas followed by periodic breathing, severe bradycardia down to 71 beats/min, and severe hemoglobin $\mathrm{O}_{2}$ desaturation down to $69 \%$.

\section{Figure 2}

Effect of nCPAP and/or caffeine treatment on A: apnea number and duration; B: bradycardia number and duration; $\mathbf{C}$ : the \% decrease in $\mathrm{SpO}_{2}$, following instillation of $0.5 \mathrm{ml}$ of milk (black column) and $\mathrm{HCl}$ (gray column) onto the laryngeal mucosa during quiet sleep. Values are expressed as means (standard deviation). ${ }^{* *} \mathrm{P}<0.05$; ${ }^{*} \mathrm{P}<0.1$. Apnea and bradycardia duration represents the sum of duration of all LCR-related apneas or bradycardias observed. 


\section{Figure 3}

Cardiorespiratory reflexes triggered in one preterm lamb following instillation of $0.5 \mathrm{ml}$ $\mathrm{HCl}$ onto the laryngeal mucosa during quiet sleep in the four conditions studied (control, nCPAP, caffeine, nCPAP + caffeine). See abbreviations in figure 1. Arterial blood $\mathrm{O}_{2}$ saturation could not be recorded because the lamb was black, hence blood color could not be analyzed by the reflectance pulse oximeter sensor. Note the severe LCR-related cardiorespiratory components with repetitive apneas, bradycardia and increased arterial pressure observed in control condition, as well as with caffeine and nCPAP + caffeine.

\section{Figure 4}

Individual cardiorespiratory responses following instillation of $0.5 \mathrm{ml} \mathrm{HCl}$ on $\mathbf{A}$ : apnea duration; B: bradycardia duration. Note the high variability of the effect of caffeine (left column) from one lamb to another, compared to the much more consistent effect of nasal CPAP (right column). 


\section{TABLES}

Table 1: Mean baseline vital signs of the 7 preterm lambs during room air breathing from birth to the last day of experimentation

\begin{tabular}{cc}
\hline Vital signs & Values \\
\hline Heart rate (beats/min) & $225(7)$ \\
Respiratory rate (breaths/min) & $69(5)$ \\
Hemoglobin $\mathrm{O}_{2}$ saturation $(\%)$ & $97(0.5)$ \\
Body temperature $\left({ }^{\circ} \mathrm{C}\right)$ & $39.9(0.1)$ \\
Glucose $(\mathrm{mmol} / \mathrm{l})$ & $5.7(2.4)$ \\
Mean weight gain/day $(\mathrm{g})$ & $227(72)$ \\
\hline
\end{tabular}

Values are expressed as mean (standard deviation) 
Table 2: Influence of nCPAP and/or caffeine treatment on baseline cardiorespiratory values during quiet sleep in 7 preterm lambs

\begin{tabular}{ccccc}
\hline Baseline values & Control & nCPAP & Caffeine & nCPAP + caffeine \\
\hline Heart rate (beats/min) & $182(28)$ & $195(33)$ & $186(39)$ & $188(34)$ \\
Respiratory rate (breaths/min) & $60(1)$ & $52(0)^{a, b}$ & $61(2)$ & $55(1)^{b}$ \\
Mean arterial pressure (mmHg) & $64(13)$ & $74(13)^{\text {a,b }}$ & $64(12)$ & $69(13)^{a}$ \\
Hemoglobin $\mathrm{O}_{2}$ saturation (\%) & $94(1)$ & $96(0)^{a}$ & $94(1)$ & $96(1)^{a, b}$ \\
\hline
\end{tabular}

Values are expressed as means (SD). Bold exponents indicate $P<0.05$, normal font exponents indicate $P<0.1$. All other $\mathrm{P}$ values are greater than $0.1{ }^{a}{ }^{a}$ : vs. control, ${ }^{b}$ : vs. caffeine, ${ }^{c}$ : vs. nCPAP/caffeine. 
Table 3: Effects of nCPAP and/or caffeine treatment on the cardiorespiratory components of LCR during quiet sleep in 7 preterm lambs

\begin{tabular}{|c|c|c|c|c|c|c|c|c|}
\hline & \multicolumn{2}{|c|}{ Control } & \multicolumn{2}{|c|}{ nCPAP } & \multicolumn{2}{|c|}{ Caffeine } & \multicolumn{2}{|c|}{ nCPAP + caffeine } \\
\hline & Milk & $\mathrm{HCl}$ & Milk & $\mathrm{HCl}$ & Milk & $\mathrm{HCl}$ & Milk & $H C l$ \\
\hline \% Decrease HR & $38(18)$ & $44(22)$ & $30(14)^{b, c}$ & $35(15)^{a, b}$ & $42(16)$ & $50(19)$ & $39(21)$ & $39(21)^{b}$ \\
\hline Minimal HR, beats/min-1 & $126(38)$ & $121(53)$ & $152(32)^{a, b}$ & $145(34)^{a, b}$ & $122(40)$ & $105(51)$ & $132(54)$ & $128(43)^{b}$ \\
\hline $\mathrm{HR}_{\min }$ occurrence time, s & $11(8)$ & $20(14)$ & $8(6)$ & $12(10)$ & $7(3)$ & $20(13)$ & $13(10)$ & $18(11)$ \\
\hline Apnea occurrence time, s & $4(5)$ & $14(12)$ & $3(5)$ & $24(25)$ & $7(7)$ & $15(9)$ & $10(13)$ & $18(12)$ \\
\hline $\mathrm{SpO}_{2 \min }$ & $87(7)$ & $87(5)$ & $94(3)^{a, b}$ & $92(5)^{a, b}$ & $89(6)$ & $87(4)^{c}$ & $92(3)^{a}$ & $91(7)^{a}$ \\
\hline $\mathrm{SpO}_{2 m i n}$ occurrence time, s & $27(15)$ & $29(15)$ & $19(7)$ & $22(8) b$ & $19(5)$ & $37(10)$ & $18(2)^{a}$ & $20(9)^{b}$ \\
\hline
\end{tabular}

Variables are expressed as means (SD). $\mathrm{HR}$, heart rate; $\mathrm{HR}_{\min }$, minimal heart rate; $\mathrm{SpO}_{2}$, hemoglobin $\mathrm{O}_{2}$ saturation; $\mathrm{SpO}_{2 m i n}$, minimal hemoglobin $\mathrm{O}_{2}$ saturation. a: vs. control, b: vs. caffeine, ${ }^{c}$ : vs. nCPAP/caffeine. Bold exponents indicate $P<0.05$, normal font exponents indicate $P<0.1$. All other $P$ values are greater than 0.1 . 
Table 4: Effects of nCPAP and/or caffeine treatment on the protective mechanisms of LCR during quiet sleep in 7 preterm lambs

\begin{tabular}{|c|c|c|c|c|c|c|c|c|}
\hline & \multicolumn{2}{|c|}{ Control } & \multicolumn{2}{|c|}{ nCPAP } & \multicolumn{2}{|c|}{ Caffeine } & \multicolumn{2}{|c|}{ nCPAP + caffeine } \\
\hline & Milk & $\mathrm{HCl}$ & Milk & $\mathrm{HCl}$ & Milk & $\mathrm{HCl}$ & Milk & $\mathrm{HCl}$ \\
\hline$\%$ Increase MAP & $21(7)$ & $21(6)$ & $12(3)^{a, b}$ & $14(4)^{a, b}$ & $26(20)$ & $22(8)$ & $16(5)^{b}$ & $14(6)^{a, b}$ \\
\hline MAP occurrence time, s & $7(3)$ & $18(13)$ & $10(10)$ & $11(9)^{a, b, c}$ & $6(3)$ & $19(8)$ & $6(1)$ & $21(12)$ \\
\hline No. swallows & $10(5)$ & $11(9)$ & $9(4)$ & $9(6)$ & $11(5)$ & $16(13)$ & $10(3)$ & $12(6)$ \\
\hline No. coughs & $0.07(0.1)$ & $2(2)$ & $0.3(0.9)$ & $1(1)^{b}$ & $1(2)$ & $5(5)$ & $0.2(0.3)$ & $2(3)^{b}$ \\
\hline No. arousals & $11 / 111$ & $6 / 111$ & $12 / 111$ & $9 / 111$ & $6 / 111$ & $6 / 111$ & $11 / 111$ & $11 / 111^{a}$ \\
\hline No. awakenings & $0 / 111$ & $4 / 111$ & $0 / 111$ & $2 / 111$ & $4 / 111$ & $6 / 111$ & $0 / 111$ & $1 / 111$ \\
\hline
\end{tabular}

Quantitative variables are expressed as means (SD) and qualitative variables (arousal and awakening) are expressed as relative frequency. MAP, mean arterial pressure; No. arousals, number of LCR with arousal/total number of LCR; No. awakenings, number of LCR with awakening/total number of LCR. a: vs. control, b: vs. caffeine, c: vs. nCPAP/caffeine. Bold exponents indicate $P<0.05$, normal font exponents indicate $P<0.1$. All other $P$ values are greater than 0.1 . 


\section{FIGURES}

\section{Figure 1:}

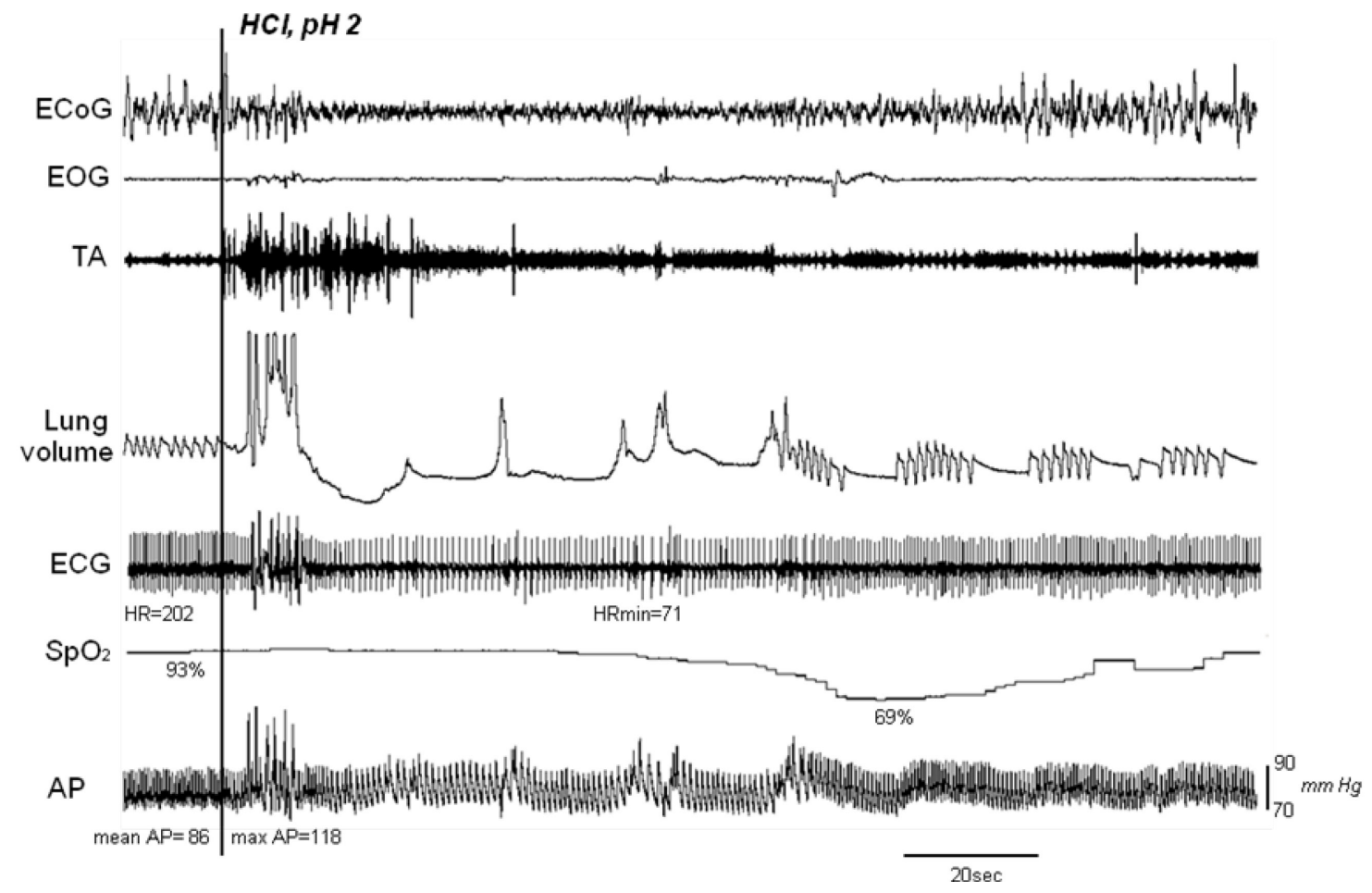


Figure 2:
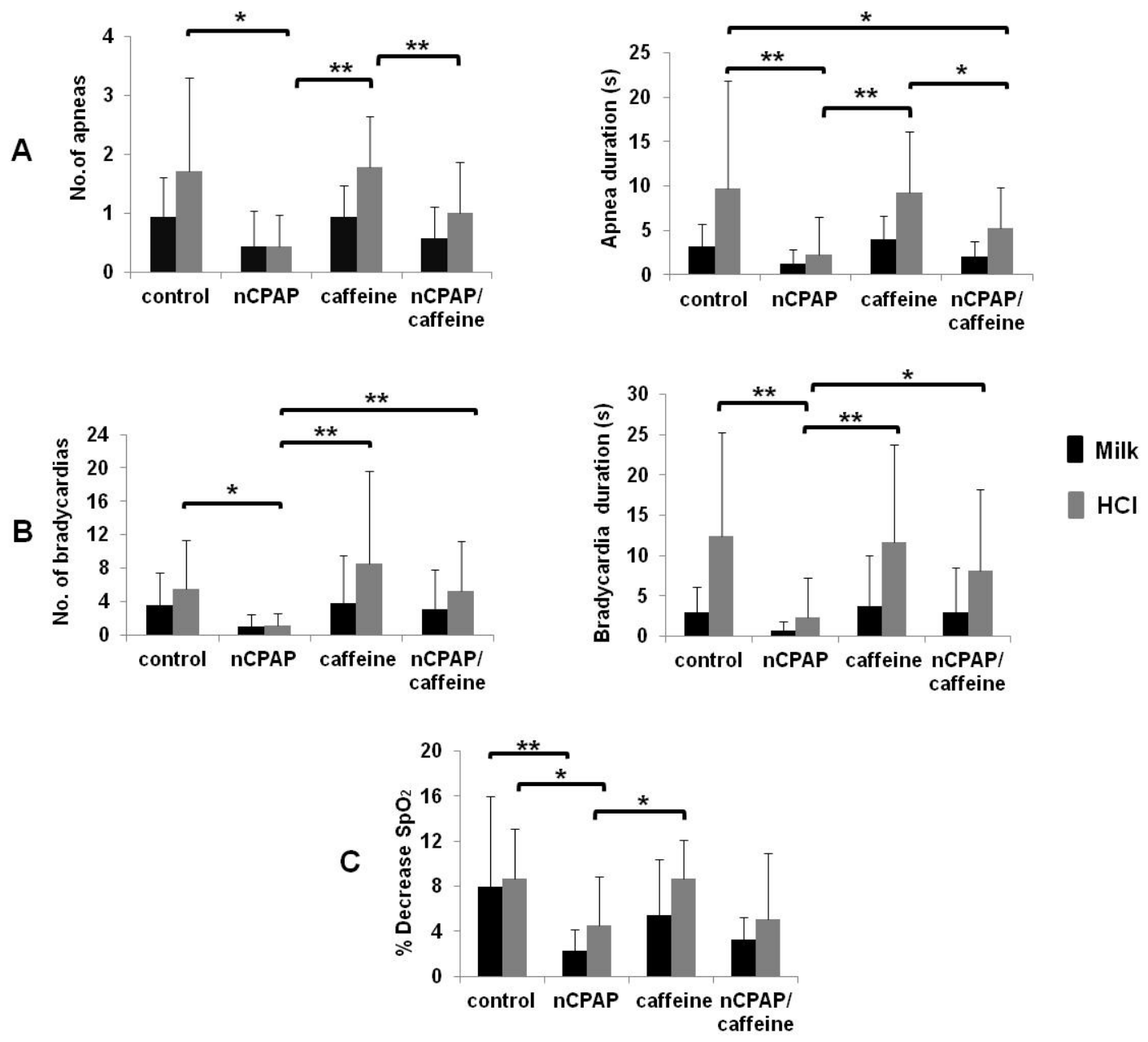
Figure 3: Effects of nCPAP and/or caffeine treatment on the cardiorespiratory components of LCR during QS
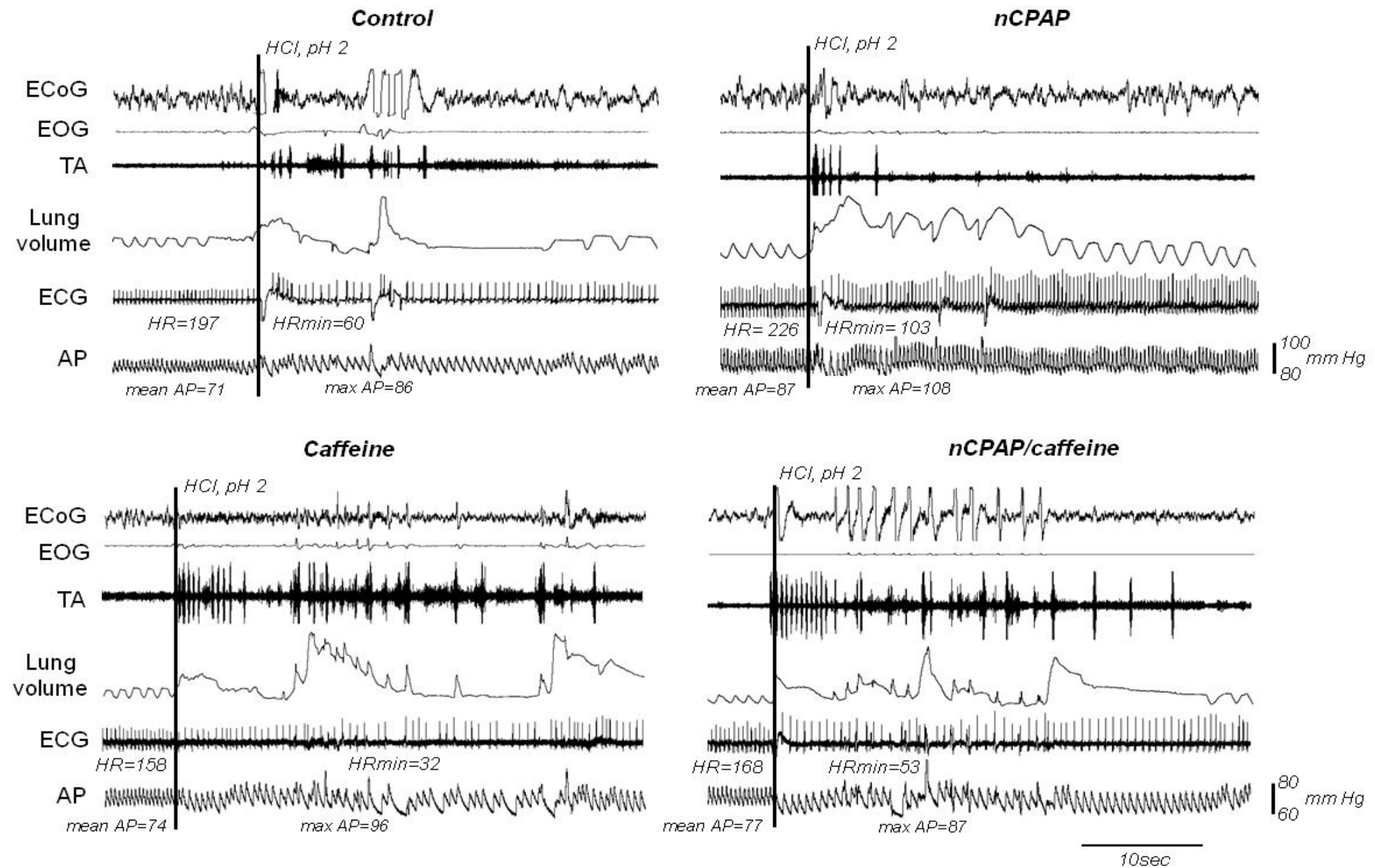
Figure 4:

\section{$\mathrm{HCl}, \mathrm{pH} 2$}
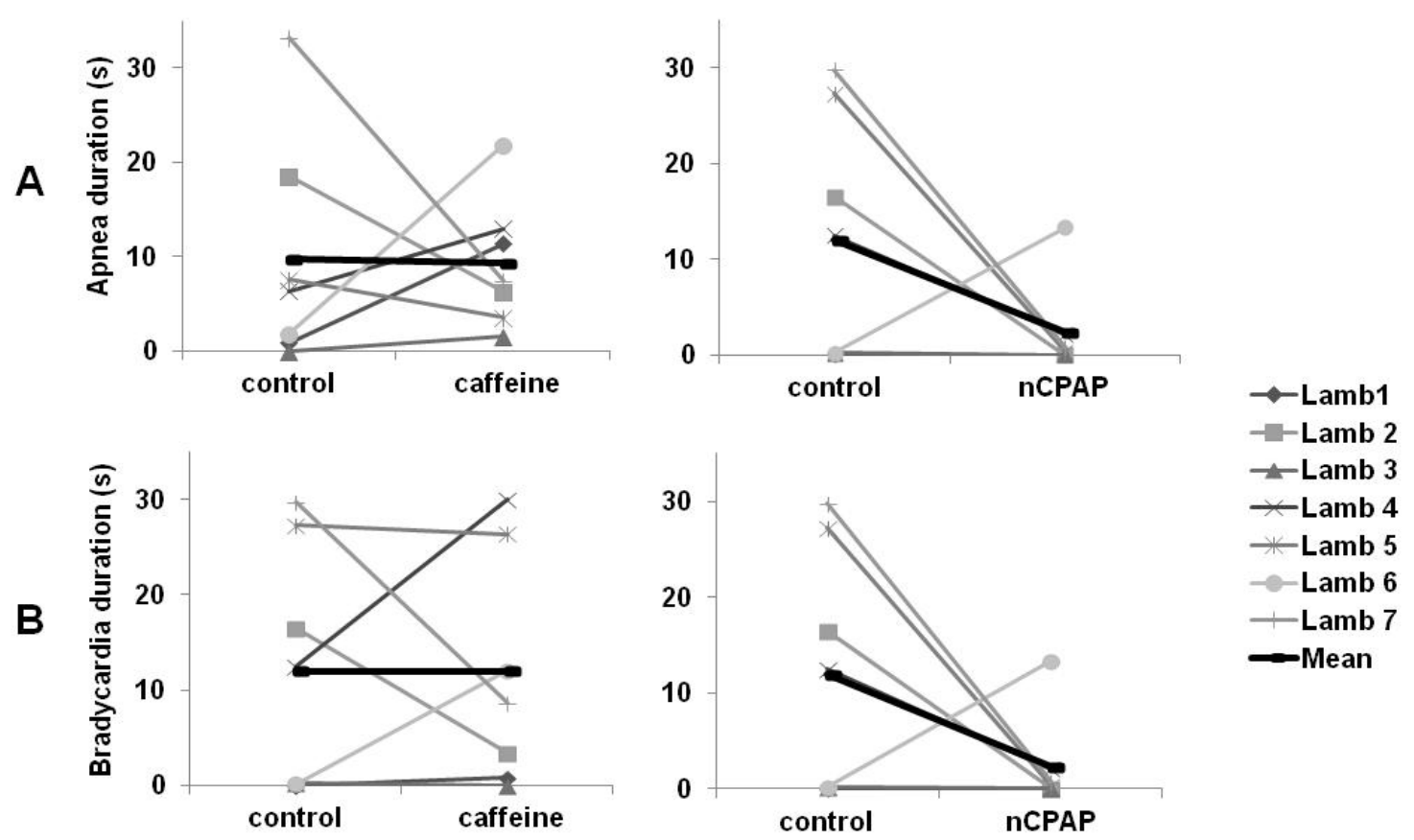